\title{
Towards the Valorization of Biomass to 5-Hydroxymethylfurfural: A Promising Biochemical and Biofuel Feedstock
}

\author{
Rey Joseph J. Ganado and Francisco C. Franco, Jr.* \\ Chemistry Department, De La Salle University, 2401 Taft Avenue, Manila
}

\begin{abstract}
The increasing oil demand and exhaustion of reserves have initiated stimulus to search for new and sustainable sources of fuels and fine chemicals. Lignocellulosic biomass turned out to be a promising and renewable feedstock for these applications. 5-hydroxymethylfurfural (HMF) is one of the most promising building blocks for bio-based chemicals that can be derived from lignocellulosic biomass which can be potentially applied for large scale production. However, one of the main factors holding its transition is the need for sustainable, green and financially feasible processes. This review provides the studies made towards catalytic systems used for HMF production, as well as the various solvents and heating system applied. Research efforts to unravel the interactions among catalysts, solvents, and heating systems are encouraged, thereby engineering a synergistic conversion system for biomass valorization.
\end{abstract}

Keywords: 5-hydroxymethylfurfural; biomass; solvent; catalysts; heating systems

\section{INTRODUCTION}

Biomass is the collective term used to identify organic matter generated either in the form of waste such as solid municipal waste or from living plants such as trees, grass, and agricultural crops and residues (Ashter, 2017). Meanwhile, lignocellulosic biomasses are those plant-derived matters that is mainly composed of carbohydrate polymers (cellulose and hemicellulose) and an aromatic polymer (lignin). It is estimated that nature produces over 150 billion tons of lignocellulosic biomass per year by photosynthesis, with only 3-4\% used by humans for food and nonfood purposes (Rackemann and Doherty, 2011). Thus, a large number of lignocellulosic biomass materials generated around the world are being discarded forgetting their potential market incentive for prospering bio-based economy and petrochemical substitute.
HMF is one of the top ten value-added biobased chemicals and an important precursor for a variety of commodity chemicals and fuels, such as 2,5-diformylfuran, furan-2,5-dicarboxylic acid, 2,5-furandimethanol, furfuryl alcohol, etc., or high calorific value biofuel, such as 2,5-dimethylfuran, 2,5-dimethyltetrahydrofuran, and 2,5- bis(alkoxymethyl)furans (Kumar et al., 2016; Zhou and Zhang, 2016). Also, other HMF derivatives can serve as a building block for diverse commodities including pharmaceuticals, polymers, resins, solvents, etc. (Gallo and Trapp, 2017). Such broad versatility has earned HMF a high market value that ranges from USD 2.0 to 300 per kilogram depending on the chemical quality (Yu et al., 2017).

The cellulose found in biomass can be used as a starting material for the production of HMF through a series of chemical reactions: (1) hydrolysis 
of cellulose into glucose, (2) isomerization of glucose to fructose, and (3) dehydration of fructose to HMF. To facilitate these tandem reactions, a broad range of catalysts have been studied, which includes Brønsted acids (e.g., $\mathrm{H}_{2} \mathrm{SO}_{4}, \mathrm{HCl}$, etc.) that assists in hydrolysis of cellulose and dehydration of fructose, as well as Lewis acids (e.g., $\mathrm{AlCl}_{3}, \mathrm{CrCl}_{3}$, etc.) that promote isomerization of glucose into HMF (Zhou et al., 2018; Zhou and Zhang, 2016). A lot of efforts has also been made on the use of solvents, such as polar protic and polar aprotic, and different heating systems, such as conventional and microwave-assisted (Yang et al., 2012).

Due to the complexity of lignocellulosic biomasses, the HMF yield when using this substrate is relatively lower compared to the use of sugars, such as glucose or fructose. In view of this, the use and development of various catalysts, solvents and heating systems, with the aim to increase the HMF yield from biomass, will be discussed in this paper.

\section{BIOMASS AS A SUBSTRATE FOR HMF SYNTHESIS}

Generally, lignocellulosic biomass consists of 40$50 \%$ cellulose, $25-30 \%$ hemicellulose and $15-30 \%$ lignin (Zhou and Zhang, 2016). The transformation of carbohydrates, cellulose, and hemicellulose, to chemicals, is of great importance to the efficient utilization of biomass. These carbohydrate components of lignocellulosic biomass are primarily consisting of $\mathrm{C} 5$ and $\mathrm{C} 6$ sugars polymers which can be hydrolyzed into individual sugar residues, such as glucose, xylose, etc. Further dehydration can produce HMF at which rehydration will lead to the formation of levulinic acid. These chemicals belong to the top 12 value-added bio-based chemicals which can serve as a versatile precursor for the synthesis of many important products such as liquid fuels, solvents, additives, plasticizers, etc. (Chen et al., 2017a; Kumar et al., 2016).

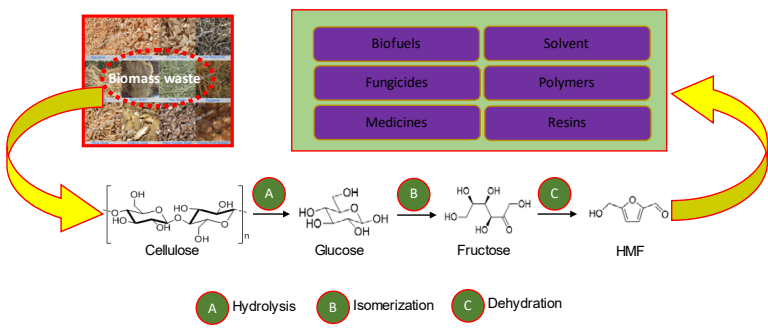

Figure 1. Chemical Pathway in the Catalytic Conversion of Biomass to HMF.

A wide range of biomass substrates, specifically agricultural residues (e.g., corncob, corn stover, corn stalk, barley husk, pinewood, maple wood, rice husk, rice straw) has been investigated as shown in
Table 1. The diverse results of HMF yield ranging from $3-52 \%$ can be attributed to the variations in the conversion systems as well as to the cellulose and hemicellulose content of the biomass.

Hot compressed water (HCW), also known as subcritical water, tends to give lower HMF yield $(<10 \%)$ even at $1: 1$ ratio of catalyst and substrate (Chareonlimkun et al., 2010). Nevertheless, the research showed that catalyst preparation procedure and calcination temperature strongly affected the catalysts reactivity. Also, catalysts prepared by coprecipitation method gained higher reactivity than those prepared by sol-gel and physical mixing method. This suggests that catalysts preparation plays role in its reactivity, thus affecting the resulting HMF yield from the substrate. Meanwhile, the use of other thermal methods, such as oil bath showed appreciable HMF yield ranging from 32-51\%. Unlike HCW, the use of unary to a more complex solvent system was common in this type of heating system, which can potentially increase the solubility of the catalysts, substrate and renders the HMF stable throughout the conversion, thus resulting to higher yield. The application of microwave also shows promising results with high HMF yield and lower reaction time compared to the previously stated heating systems. For example, Zhang and colleagues demonstrated that HMF yield of $45-52 \%$ can be obtained within 3 minutes from corn stalk, rice straw and pinewood by using an ionic liquid as a solvent, $\mathrm{CrCl}_{3} \cdot 6 \mathrm{H}_{2} \mathrm{O}$ as a catalyst, and microwave as a heating system. The conversion was very rapid and did not require any pretreatment, thereby making this method valuable to facilitate the cost-effective conversion of biomass into biofuels and bio-based products (Zhang and Zhao, 2010).

These results highlight the significance of catalysts, solvents and heating systems on the efficient biomass conversion to HMF, but there's insufficient information about their corresponding distribution. Such knowledge is needed to facilitate the maneuvering of catalyst and solvent to maximize the HMF production and increase the system capacity. Thus, the various catalysts, solvents and heating systems will be discussed in the subsequent sections.

\section{CATALYSTS}

Acid catalysts are typically used for the conversion of sugars into HMF. During the acid-catalyzed hydrolysis of polysaccharide, protons weaken the $\mathrm{O}$-glycosidic bond by attacking the oxygen atom of the linkage. This results in the breakdown into individual sugar residues of the polysaccharide. Fructose dehydration illustrates a similar catalytic mechanism: proton attaches to the $\mathrm{C} 2$ hydroxyl 
Table 1. Biomass Feedstock for HMF Production under Different Catalytic Systems.

\begin{tabular}{|c|c|c|c|c|c|c|c|}
\hline Substrate & Catalyst & Solvent & Phase system & Heating system & Conditions & HMF yield & Reference \\
\hline Barley husk, $25 \mathrm{mg}$ & $\begin{array}{l}\text { Sulphanilic acid, } 48 \\
\text { mol\% }\end{array}$ & $\begin{array}{l}\text { Water-DMSO/ } \\
\text { 2-butanol-MIBK } \\
(0.3,0.7 / 0.6,1.4 \\
\mathrm{mL}), 3 \mathrm{~mL}\end{array}$ & Biphasic & Thermal, Oil bath & $423 \mathrm{~K}, 60 \mathrm{~min}$ & $41 \%$ & $\begin{array}{l}\text { (Mirzaei and } \\
\text { Karimi, 2016) }\end{array}$ \\
\hline Corncob, $25 \mathrm{mg}$ & SPTPA, 30mg & GVL, $2 \mathrm{~mL}$ & Monophasic & Thermal, Oil bath & $448 \mathrm{~K}, 30 \mathrm{~min}$ & $32.3 \%$ & (Zhang et al., 2017) \\
\hline Corncob, $0.1 \mathrm{~g}$ & $\mathrm{TiO}_{2}-\mathrm{ZrO}_{2}, 0.1 \mathrm{~g}$ & Water & Monophasic & $\begin{array}{l}\text { Hot compressed } \\
\text { water }\end{array}$ & $523 \mathrm{~K}, 5 \mathrm{~min}$ & $8.6 \%$ & $\begin{array}{l}\text { (Chareonlimkun et } \\
\text { al., 2010) }\end{array}$ \\
\hline Corn stalk, $0.1 \mathrm{~g}$ & $\mathrm{CrCl}_{3} \cdot 6 \mathrm{H}_{2} \mathrm{O}, 10 \mathrm{mg}$ & {$\left[\mathrm{C}_{4} \mathrm{mim}\right] \mathrm{Cl}, 2 \mathrm{~g}$} & Monophasic & Microwave & $400 \mathrm{~W}, 3 \mathrm{~min}$ & $45 \%$ & $\begin{array}{l}\text { (Zhang and Zhao, } \\
2010)\end{array}$ \\
\hline Corn stover, 5\% wt. & $\mathrm{FeCl}_{3}, 1 \%$ wt. & $\begin{array}{l}\text { THF-water }(1: 1 \\
\mathrm{v} / \mathrm{v})\end{array}$ & Monophasic & $\begin{array}{l}\text { Thermal, Parr } \\
\text { reactor }\end{array}$ & $443 \mathrm{~K}, 80 \mathrm{~min}$ & $45 \%$ & (Cai et al., 2014) \\
\hline Eucalyptus, $0.4 \mathrm{~g}$ & Levulinic acid, $0.1 \mathrm{~g}$ & $\begin{array}{l}\text { MTHF/water (1:1 } \\
\text { w/w), } 20 \mathrm{~g}\end{array}$ & Biphasic & $\begin{array}{l}\text { Thermal, Parr } \\
\text { reactor }\end{array}$ & $453 \mathrm{~K}, 60 \mathrm{~min}$ & $93 \mathrm{mg} \mathrm{L}^{-1}$ & $\begin{array}{l}\text { (Seemala et al., } \\
\text { 2016) }\end{array}$ \\
\hline $\begin{array}{l}\text { Maple wood, 5\% } \\
\text { wt. }\end{array}$ & $\mathrm{FeCl}_{3}, 1 \%$ wt. & $\begin{array}{l}\text { THF-water }(1: 1 \\
\mathrm{v} / \mathrm{v})\end{array}$ & Monophasic & $\begin{array}{l}\text { Thermal, Parr } \\
\text { reactor }\end{array}$ & $443 \mathrm{~K}, 60 \mathrm{~min}$ & $51 \%$ & (Cai et al., 2014) \\
\hline Pinewood, $0.4 \mathrm{~g}$ & Levulinic acid, $0.1 \mathrm{~g}$ & $\begin{array}{l}\text { MTHF/water (1:1 } \\
\text { w/w), } 20 \mathrm{~g}\end{array}$ & Biphasic & $\begin{array}{l}\text { Thermal, Parr } \\
\text { reactor }\end{array}$ & $453 \mathrm{~K}, 60 \mathrm{~min}$ & $897 \mathrm{mg} \mathrm{L}^{-1}$ & $\begin{array}{l}\text { (Seemala et al., } \\
\text { 2016) }\end{array}$ \\
\hline Pinewood, $0.1 \mathrm{~g}$ & $\mathrm{CrCl}_{3} \cdot 6 \mathrm{H}_{2} \mathrm{O}, 10 \mathrm{mg}$ & {$\left[\mathrm{C}_{4} \operatorname{mim}\right] \mathrm{Cl}, 2 \mathrm{~g}$} & Monophasic & Microwave & 400W, $3 \mathrm{~min}$ & $47 \%$ & $\begin{array}{l}\text { (Zhang and Zhao, } \\
2010)\end{array}$ \\
\hline Rice husk, $0.1 \mathrm{~g}$ & $\mathrm{TiO}_{2}-\mathrm{ZrO}_{2}, 0.1 \mathrm{~g}$ & Water & Monophasic & $\begin{array}{l}\text { Hot compressed } \\
\text { water }\end{array}$ & $523 \mathrm{~K}, 5 \mathrm{~min}$ & $-3.3 \%$ & $\begin{array}{l}\text { (Chareonlimkun et } \\
\text { al., 2010) }\end{array}$ \\
\hline Rice straw, $0.1 \mathrm{~g}$ & $\mathrm{CrCl}_{3} \cdot 6 \mathrm{H}_{2} \mathrm{O}, 10 \mathrm{mg}$ & {$\left[\mathrm{C}_{4} \mathrm{mim}\right] \mathrm{Cl}, 2 \mathrm{~g}$} & Monophasic & Microwave & $400 \mathrm{~W}, 3 \mathrm{~min}$ & $52 \%$ & $\begin{array}{l}\text { (Zhang and Zhao, } \\
2010)\end{array}$ \\
\hline Straw, $25 \mathrm{mg}$ & $\begin{array}{l}\text { Sulphanilic acid, } 48 \\
\text { mol\% }\end{array}$ & $\begin{array}{l}\text { Water-DMSO/ } \\
\text { 2-butanol-MIBK } \\
(0.3,0.7 / 0.6,1.4 \\
\mathrm{mL}), 3 \mathrm{~mL}\end{array}$ & Biphasic & Thermal, Oil bath & $423 \mathrm{~K}, 60 \mathrm{~min}$ & $41 \%$ & $\begin{array}{l}\text { (Mirzaei and } \\
\text { Karimi, 2016) }\end{array}$ \\
\hline Sugar bagasse, $0.1 \mathrm{~g}$ & $\mathrm{TiO}_{2}-\mathrm{ZrO}_{2}, 0.1 \mathrm{~g}$ & Water & Monophasic & $\begin{array}{l}\text { Hot compressed } \\
\text { water }\end{array}$ & $523 \mathrm{~K}, 5 \mathrm{~min}$ & $-6.7 \%$ & $\begin{array}{l}\text { (Chareonlimkun et } \\
\text { al., 2010) }\end{array}$ \\
\hline
\end{tabular}


group of fructose to initiate the elimination of the first water molecule, resulting in a carbonium ion. Such intermediate transforms into an enol, which is subsequently condensed to give HMF by releasing two more water molecules (Yu and Tsang, 2017). Generally, these acid catalysts can be categorized by phase, as homogeneous or heterogeneous catalyst, or by function, such as Lewis and Brønsted acid.

Homogeneous Catalysts. Homogeneous acids, such as $\mathrm{HCl}, \mathrm{H}_{2} \mathrm{SO}_{4}, \mathrm{HNO}_{3}$, etc., were the popular methods for a long time to synthesize HMF from lignocellulosic biomass due to their faster reaction and lower amount of catalyst needed compared to heterogeneous acids. This method has been used in the first commercial-scale plant for the conversion of lignocellulosic biomass. Although the use of these acids for hydrolysis reactions was effective, these homogeneous catalysts suffered from drawbacks. One of which is the corrosive reaction conditions that require special materials for reactor construction and chemical recovery systems. Thus, this disadvantage can increase the capital and operation cost for production. Moreover, depending on the recovery process, a significant amount of wastes is produced causing environmental problems (Chen et al., 2017a; Ya'aini et al., 2012). As an alternative, heterogeneous acid catalysts have been promoted since these catalysts can overcome the problems occurred in homogeneous catalysts.

Heterogenous Catalysts. Unlike homogeneous catalysts, heterogeneous or solid acids offer potential due to their simple and energy efficient separation, reusable nature, limited corrosion and selectivity (Rackemann and Doherty, 2011). Solid acids includes zeolites (Lima et al., 2016), ion-exchange resins (Rinaldi et al., 2008), metal-oxides (Gliozzi et al., 2014), functionalized silica (Takagaki et al., 2011), carbonaceous solid acid ( $\mathrm{Hu}$ et al., 2015), etc. Among the above mentioned conventional solid acid catalysts, the cheaper carbon-based solid acid catalysts have been identified as a novel type of solid acid catalysts in recent years. This type of catalyst is generally prepared by the incomplete carbonization of glucose or cellulose and the subsequent sulfonation, a Brønsted acid, of the resulting amorphous carbon (Hu et al., 2015). Despite the economic advantage of carbon-based solid acid, this type of catalyst possessed some drawbacks, which includes low yield due to weak interaction to cellulose and cannot be readily separated to the formed solid residues that affect its recyclability (Lai et al., 2011). This weakness has been overcome by the addition of chloride group and magnetic property to the solid acid ( $\mathrm{Hu}$ et al., 2016; Huang and Fu, 2013; Lai et al., 2011; Li et al., 2018).
In comparison to carboxylic (-COOH) and phenolic hydroxyl $(-\mathrm{OH})$ groups, the $-\mathrm{Cl}$ groups with a stronger electronegativity could not only improve the adsorbability to cellulose chain but also enhance the acidity of $-\mathrm{SO}_{3} \mathrm{H}$ groups ( $\mathrm{Hu}$ et al., 2016). Moreover, the $-\mathrm{Cl}$ groups can serve as a cellulosebinding domain because it is able not only to form stronger hydrogen bonds with hydroxyl groups of cellulose but also able to disrupt intra- and interhydrogen bonds of cellulose, which will enhance the swelling and dissolution of cellulose (Shuai and Pan, 2012). For this reason, chloride has been widely involved in cellulose solvents, such as [BMIM]Cl, and chloride-containing ionic liquids (Rinaldi et al., 2008; Shen et al., 2018). Meanwhile, the addition of magnetic property to the carbon-based solid acid involves the use of magnetite, $\mathrm{Fe}_{3} \mathrm{O}_{4}$. This is typically done by co-carbonization of $\mathrm{FeCl}_{3}$ with the solid acid or by synthesizing $\mathrm{Fe}_{3} \mathrm{O}_{4}$ separately before impregnating with the partially carbonized support (Hu et al., 2015; Li et al., 2018). The magnetic property of catalyst is important because although cellulose can be degraded into soluble sugars, the lignin components of the actual cellulosic biomass cannot be converted and humins sometimes form as solid residues, both of which are difficult to separate from the recovered solid catalysts (Huang and $\mathrm{Fu}$, 2013).

Brønsted Acids. It is well-known that Brønsted acids (e.g., $\mathrm{HCl}, \mathrm{H}_{2} \mathrm{SO}_{4}$ ) can facilitate the catalytic hydrolysis of cellulose into its individual glucose unit and aids in the dehydration of fructose to HMF (Portillo Perez et al., 2018). Brønsted acid-catalyzed conversion of carbohydrates in aqueous solutions proceeds through a complex network of elementary steps such as protonation, deprotonation, isomerization, dehydration, hydration, and intramolecular hydrogen transfer. These reactions involve many intermediates, which are prone to side-reactions. The mechanism, kinetics, and thermodynamics of sugar conversion have been the subject of many experimental and theoretical

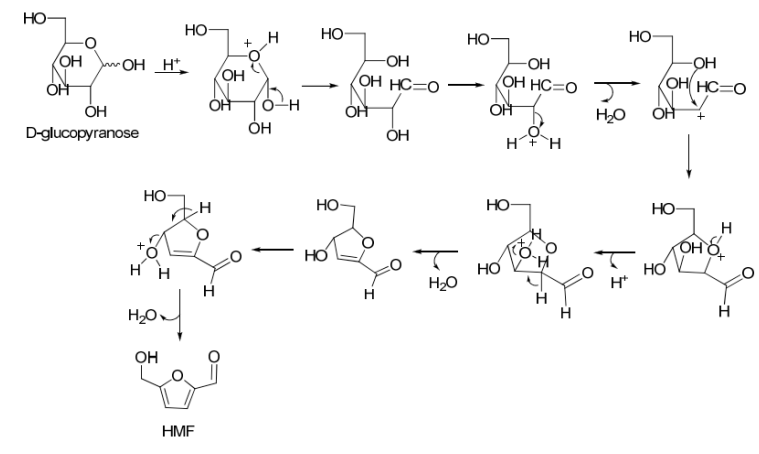

Figure 2. Proposed Mechanism for the Conversion of Glucose into HMF by a Bronsted Acid Catalyzed Reaction (Wang et al., 2012a). 
studies with the main focus on fructose dehydration to HMF (Yang et al., 2012). For example, Wang and colleagues proposed that the formation of HMF may follow a mechanism in which the open-chain form of glucose is dehydrated at the $\mathrm{C} 2$ position, forming a carbocation which reacts with the hydroxyl group at C5 position, forming tetrahydro-3,4-dihydroxy-5(hydroxymethyl)-2-furaldehyde followed by further dehydration to form HMF (Wang et al., 2012a).

Lewis Acids. Brønsted acids have been extensively tested and studied catalysts. However, most of them are corrosive and toxic in nature. As an alternative, Lewis acids, particularly in the forms of their salts, offer advantages such as easier recovery and less corrosiveness (Portillo Perez et al., 2018). Lewis acids are able to catalyze the isomerization of glucose to fructose, which is a critical step in in the conversion of cellulose to HMF because glucose released from glucan hydrolysis has a stable six-membered pyranose structure against the dehydration reaction while fructose is more reactive ( $\mathrm{Yu}$ and Tsang, 2017). Despite the known role of Lewis acids in the isomerization process of glucose and fructose, numerous studies already suggest that these acids can be a stand-alone catalyst in converting hexoses into HMF (Delidovich and Palkovits, 2016; Jia et al., 2017, 2014).

Combination of Brønsted and Lewis acids. Given that Brønsted acids promote protonation and Lewis acids deprotonation, several researches were conducted to investigate the synergistic effect of the two catalysts during the dehydration reaction. The results of Dumesic et al. (Wang et al., 2012b) showed that the conversion of glucose into HMF in the presence of Lewis and Brønsted acidity proceeds through a tandem pathway involving isomerization of glucose into fructose, followed by dehydration of fructose to HMF. For this reason, researchers have been leaning towards a combined approach, which exploits both Brønsted acids' capabilities to promote hydrolysis, and Lewis acids' capability to isomerize and dehydrate hexoses.

A study suggested that the $\mathrm{B}: \mathrm{L}$ acids ratio must be maneuvered to promote faster kinetics of the desirable reactions (i.e., hydrolysis, isomerization, and dehydration) relative to those of the undesirable pathways (i.e., rehydration, polymerization) for higher HMF yield (Yu et al., 2017). Lewis acid could induce more pronounced polymerization compared to Brønsted acid, despite its enhancement on glucose isomerization. For instance, the rate coefficients of the polymerization reactions mediated by $\mathrm{AlCl}_{3}$ $\left(0.08-0.23 \mathrm{~min}^{-1}\right)$ were higher than $\mathrm{HCl}(0.05-0.13$ $\left.\mathrm{min}^{-1}\right)$ in an aqueous medium (Zhang et al., 2015).

\section{SOLVENTS}

Solvolysis has an advantage over hydrolysis in such that solvents can be used to alter the properties of the reaction mixture in promoting more selective reactions and allows reactions to occur at lower temperatures (Rackemann and Doherty, 2011). Moreover, the solvent may serve multiple roles during the biomass conversion: dissolving the substrates and catalyst for desirable reactions; stabilizing the substrates, intermediates, and products to enhance the thermodynamic equilibrium for higher product yield; and acting as a catalyst to improve the reaction kinetics (Yu and Tsang, 2017). Solvents typically used for biomass conversion can be divided into four categories: polar protic, polar aprotic, ionic liquids and deep eutectic solvents.

Polar Aprotic Solvent. Water is an example of a polar protic solvent, which provides protons and high polarity (Yu and Tsang, 2017). As reported in the literature, water is the most ideal solvent for the dehydration of fructose into HMF in theory. This is because water has great advantages in economic viability, ecological superiority, and technological convenience. Unfortunately, the dehydration of fructose is non-selective in pure water, leading to a low yield of HMF, which is caused by the formation of an abundance of by-products such as levulinic acid (LA), formic acid (FA) and humins (Hu et al., 2015). Moreover, HMF has high solubility in water which results in low HMF selectivity and difficulty in HMF isolation, which would limit industrial scale application of a simple aqueous phase (Yang et al., 2013).

Polar Protic Solvent. Meanwhile, polar aprotic solvents have moderate polarity and no acidic proton. Examples of polar aprotic solvents are dimethyl sulfoxide (DMSO), tetrahydrofuran (THF), methyl isobutyl ketone (MIBK), N,N-dimethylacetamide (DMA) and other biomass-derived solvents such as $\gamma$-Valerolactone (GVL) (Gliozzi et al., 2014). Among these solvents, DMSO offers advantages for dehydration of fructose as it eliminates HMF decomposition to levulinic and formic acids while inhibiting the formation of humins (Bozell and Petersen, 2010; Yang et al., 2013). However, it is difficult to separate HMF from DMSO due to its high boiling point (Zhou and Zhang, 2016). For this reason, the biphasic system was preferred in which the hydrolysis and dehydration reactions occur in the aqueous phase, while the organic phase is used to timely extract HMF from the aqueous layer. Nonetheless, mixtures of DMSO with $\mathrm{H}_{2} \mathrm{O}$ are preferable so as to prevent the dehydration of glucose to levoglucosan, facilitate the bridging of the dehydration process with a primary cellulose/ 
biomass hydrolysis step in aqueous solution and contribute to the lowering of the use of organic solvents (Marianou et al., 2018).

Ionic Liquids (ILs). Ionic liquids, ILs, which molten salts that are liquid at room temperature, are an important class of chemicals that can act as both a solvent and catalyst for the production of HMF (Gliozzi et al., 2014). ILs can serve as good solvents for various carbohydrates and are more environment-friendly than volatile organic solvents. Other attractive properties of ILs include low vapor pressure, non-flammability, and thermal stability. ILs offer similar advantages to heterogeneous catalysts in that they can usually be easily separated from the reaction mixture for reuse and retain high activity plus they offer the advantage of allowing the reaction process to be conducted at much lower temperatures $\left(<100^{\circ} \mathrm{C}\right)$ (Rackemann and Doherty, 2011). However, ILs are expensive, especially for industrial applications, despite they are easily separated. Therefore, the addition of organic solvents to ILs as reaction media can be a good option to reduce cost by using less ILs (Guo et al., 2012).

Deep Eutectic Solvents (DESs). Deep eutectic solvents (DESs) are green and efficient alternative to ILs for the biomass pretreatment and conversion. DESs are a special mixture of two components: hydrogen-bonding donor (HBD) and hydrogenbonding acceptor (HBA) (Chen and $\mathrm{Mu}, 2019$ ). Generally, the melting point of the DES is lower than the melting points of each of its starting components, and are easily produced by just mixing two or more compounds and heating to around $80^{\circ} \mathrm{C}$ or freeze drying without the subsequent need of any complex purification step (Cunha and Fernandes, 2018). One example of DES is under the trade name Reline, which is a mixture of choline chloride and urea. When these two a are mixed at the molar ratio of $1: 2$, a eutectic occurs at a freezing point of $12{ }^{\circ} \mathrm{C}$ which is significantly lower than that of its original precursors (Malaeke et al., 2018).

Studies have shown that cellulose and starch are soluble in choline chloride (ChoCl) DESs and that cellulose can be de-crystallized in this solvent, making it interesting for HMF production. Even more interesting is the fact that carbohydrates can themselves form DESs at low temperatures, allowing for highly sugar-concentrated systems (Biswas et al., 2006; Chen and $\mathrm{Mu}, 2019)$. DESs prepared with organic renewable materials were very effective in transforming fructose to HMF. Particularly promising was the use of $\mathrm{ChoCl} /$ citric acid, both in the anhydrous and monohydrate forms, where HMF yields of over $70 \%$ were obtained at only $80^{\circ} \mathrm{C}$ and for 1 hour of reaction. While the anhydrous form of citric acid performed slightly better, it was noted that it increased the viscosity of the system and that its use was not energy efficient. To improve the results, the researchers used a biphasic system consisting of ethyl acetate (AcOEt) and $\mathrm{ChoCl} /$ citric acid, which increased the HMF yields to up to $86 \%$ (Hu et al., 2008).

\section{HEATING SYSTEMS}

The more sophisticated and recalcitrant structures in the biomass materials may require a higher temperature for conversion than model compounds, which indicates the possibility of more side products and less selectivity (Chen et al., 2017b). Therefore, the efficient heating system is also necessary for the conversion of biomass into desired products. Currently, two heating systems are being employed in a variety of studies for biomass conversion into value-added platform chemicals: conventional and microwave.

Conventional. Conventional heating is the most widely used method in biomass conversion. Zhang, et. al. (Zhang et al., 2017), showed that corncob can be converted into furfural and HMF using a porous polytriphenylamine- $\mathrm{SO}_{3} \mathrm{H}$ (SPTPA) solid acid in lactone solvents. Under optimized conditions, a maximum yield of $32.3 \%$ for HMF was obtained. In another study conducted by Yan, et. al. (Yan et al., 2014), 44.1\% HMF yield was achieved using conventional heating at $150^{\circ} \mathrm{C}$ using carbonaceous solid acid and an ionic liquid. These show that conventional heating can be employed in a variety of solvents and catalysts without affecting its catalytic performance when being applied to actual biomass. However, conventional heating often involves a long reaction time due to low heat transfer efficiency. Thus, there is a growing interest in using microwave for biomass conversion.

Microwave-assisted. Microwave can effectively shorten the reaction time, improves the product yields, and diminishes the side reactions ( $\mathrm{Yu}$ and Tsang, 2017). In addition, the selective dielectric heating of microwave could improve heat transfer, thus leading to a higher reaction rate due to the effectiveness of structure disruption and release of cell constituents from the bio-waste (Chen et al., 2017a). Moreover, a study had shown that the yield of glucose from cellulose was almost 50 times higher than conventional heating under similar conditions (Fan et al., 2013). Thus, microwave shows a promising heating system for biomass conversion compared to conventional heating. Zhang et. al., demonstrated that HMF yield of $45-52 \%$ can be obtained from corn stalk, rice straw and pine wood using microwave in the presence of $\mathrm{CrCl}_{3}$ in an ionic 
liquid within 3 minutes. Therefore, this method should be valuable in facilitating energy-efficient and cost-effective conversion of biomass into biofuels and platform chemicals.

\section{CONCLUSIONS}

This review demonstrated the various advancement in catalysts and HMF production processes in recent years. It was also highlighted that HMF, an important versatile bio-based chemical, can be produced from renewable resources that we commonly treat as waste, such as biomass. HMF has the potential for the production of clean liquid fuels (e.g., 2,5-dimethylfuran, 2,5-dimethyltetrahydrofuran) by a hydrogenation reaction. In an oxidation reaction, HMF led to commercially important chemicals such as 2,5-diformylfuran and 2,5-furandicarboxylic acid. However, a simple and reliable way of acquiring HMF from biomass remains as a bottleneck due to its complex resource that requires a wide palette of technologies to ensure effective processing of all its constituents. Also, the need for production processes that are feasible for large scale production, green and sustainable is of great importance for their potential market incentive for flourishing bio-based economy and petrochemical substitute. Based on this context, the use of renewable bifunctional-heterogenous catalysts, deep eutectic solvents and application of microwave as a heating system will thrive for a greener process in converting a sustainable substrate, such biomass, into future fuel and biochemicals.

\section{REFERENCES}

Ashter SA. Technology and Applications of Polymers Derived from Biomass, 1 st ed. PLASTICS DESIGN LIBRARY (PDL), Chadds Ford, PA, USA; 2017

Biswas A, Shogren RL, Stevenson DG, Willett JL, Bhowmik PK. Ionic liquids as solvents for biopolymers: Acylation of starch and zein protein. Carbohydr Polym. 2006; 66: 546-550.

Bozell JJ, Petersen GR. Technology development for the production of biobased products from biorefinery carbohydrates-the US Department of Energy's “Top 10" revisited. Green Chem. 2010; 12: 539.

Cai CM, Nagane N, Kumar R, Wyman CE. Coupling metal halides with a co-solvent to produce furfural and 5-HMF at high yields directly from lignocellulosic biomass as an integrated biofuels strategy. Green Chem. 2014; 16: 3819-3829.

Chareonlimkun A, Champreda V, Shotipruk A, Laosiripojana N. Catalytic conversion of sugarcane bagasse, rice husk and corncob in the presence of $\mathrm{TiO}_{2}, \mathrm{ZrO}_{2}$ and mixed-oxide $\mathrm{TiO}_{2}-\mathrm{ZrO}_{2}$ under hot compressed water $(\mathrm{HCW})$ condition. Bioresour Technol. 2010; 101: 4179-4186.

Chen SS, Maneerung T, Tsang DCW, Ok $\mathrm{YS}$, Wang $\mathrm{CH}$. Valorization of biomass to hydroxymethylfurfural, levulinic acid, and fatty acid methyl ester by heterogeneous catalysts. Chem Eng J. 2017a; 328: 246-273.

Chen SS, Maneerung T, Tsang DCWW, Sik Y, Wang $\mathrm{CH}$, Ok YS, Wang CH. Valorization of biomass to hydroxymethylfurfural, levulinic acid, and fatty acid methyl ester by heterogeneous catalysts. Chem Eng J. 2017b; 328: 246-273.

Chen Y, Mu T. Application of deep eutectic solvents in biomass pretreatment and conversion. Green Energy Environ. In Press. 2019; 1-21.

Cunha SC, Fernandes JO. Extraction techniques with deep eutectic solvents. TrAC - Trends Anal Chem. 2018; 105: 225-239.

Delidovich I, Palkovits R. Catalytic Isomerization of Biomass-Derived Aldoses: A Review. ChemSusChem. 2016; 9: 547-561.

Fan J, De bruyn M, Zhu Z, Budarin V, Gronnow M, Gomez LD, Macquarrie D, Clark J. Microwaveenhanced formation of glucose from cellulosic waste. Chem Eng Process Process Intensif. 2013; 71: 37-42.

Gallo JMR, Trapp MA. The chemical conversion of biomass-derived saccharides: An overview. J Braz Chem Soc. 2017; 28: 1586-1607.

Gliozzi G, Innorta A, Mancini A, Bortolo R, Perego C, Ricci M, Cavani F. Zr/P/O catalyst for the direct acid chemo-hydrolysis of non-pretreated microcrystalline cellulose and softwood sawdust. Appl Catal B Environ. 2014; 145: 24-33.

Guo F, Fang Z, Zhou TJ. Conversion of fructose and glucose into 5-hydroxymethylfurfural with ligninderived carbonaceous catalyst under microwave irradiation in dimethyl sulfoxide-ionic liquid mixtures. Bioresour Technol. 2012; 112: 313-318.

Hu L, Li Z, Wu Z, Lin L, Zhou S. Catalytic hydrolysis of microcrystalline and rice straw-derived cellulose over a chlorine-doped magnetic carbonaceous solid acid. Ind Crops Prod. 2016; 84: 408-417.

Hu L, Tang X, Wu Z, Lin L, Xu J, Xu N, Dai B. Magnetic lignin-derived carbonaceous 
catalyst for the dehydration of fructose into 5-hydroxymethylfurfural in dimethylsulfoxide. Chem Eng J. 2015; 263: 299-308.

Hu S, Zhang Z, Zhou Y, Han B, Fan H, Li W, Song J, Xie Y. Conversion of fructose to 5-hydroxymethylfurfural using ionic liquids prepared from renewable materials. Green Chem. 2008; 10: 1280-1283.

Huang YB, Fu Y. Hydrolysis of cellulose to glucose by solid acid catalysts. Green Chem. 2013; 15: 1095-1111.

Jia S, He Y, Wang G. Dimethylsulfoxide/ Water Mixed Solvent Mediated Synthesis of 5-Hydroxymethylfurfural from Galactose with Aluminum Salt Catalyst. ChemistrySelect. 2017; 2: 2356-2362.

Jia S, Xu Z, Zhang ZC. Catalytic conversion of glucose in dimethylsulfoxide / water binary mix with chromium trichloride : Role of water on the product distribution. Chem Eng J. 2014; 254: 333-339.

Kumar P, Deepak A, Prakash O, Kalra A. Synthesis of hydroxymethylfurfural from cellulose using green processes: A promising biochemical and biofuel feedstock. Chem Eng Sci. 2016; 142:318-346.

Lai D, Deng L, Guo Q, Fu Y. Hydrolysis of biomass by magnetic solid acid. Energy Environ Sci. 2011; 4: 3552-3557.

Li XX, Lei T, Wang Z, Li XX, Wen M, Yang M, Chen G, He X, Xu H, Guan Q, Li Z. Catalytic pyrolysis of corn straw with magnetic solid acid catalyst to prepare levulinic acid by response surface methodology. Ind Crops Prod. 2018; 116: 73-80.

Lima TM, Lima CGS, Rathi AK, Gawande MB, Tucek J, Urquieta-González EA, Zbořil R, Paixão MW, Varma RS. Magnetic ZSM-5 zeolite: a selective catalyst for the valorization of furfuryl alcohol to $\gamma$-valerolactone, alkyl levulinates or levulinic acid. Green Chem. 2016; 18: 5586-5593.

Malaeke H, Housaindokht MR, Monhemi H, Izadyar M. Deep eutectic solvent as an efficient molecular liquid for lignin solubilization and wood delignification. J Mol Liq. 2018; 263: 193-199.

Marianou AA, Michailof CM, Pineda A, Iliopoulou EF, Triantafyllidis KS, Lappas AA. Effect of Lewis and Brønsted acidity on glucose conversion to 5-HMF and lactic acid in aqueous and organic media. Appl Catal A Gen. 2018; 555: 75-87.
Mirzaei HM, Karimi B. Sulphanilic acid as a recyclable bifunctional organocatalyst in the selective conversion of lignocellulosic biomass to 5-HMF. Green Chem. 2016; 18: 2282-2286.

Portillo Perez G, Mukherjee A, Dumont MJ. Insights into HMF catalysis. J Ind Eng Chem. 2019; 70: $1-34$.

Rackemann DW, Doherty WO. The conversion of lignocellulosics to levulinic acid. Biofuels Bioprod Biorefining. 2011; 5(2): 198-214

Rinaldi R, Palkovits R, Schüth F. Depolymerization of cellulose using solid catalysts in ionic liquids. Angew Chemie Int Ed. 2008; 47: 8047-8050.

Seemala B, Haritos V, Tanksale A. Levulinic Acid as a Catalyst for the Production of 5-Hydroxymethylfurfural and Furfural from Lignocellulose Biomass. ChemCatChem. 2016; 8: 640-647.

Shen F, Guo T, Bai C, Qiu M, Qi X. Hydrolysis of cellulose with one-pot synthesized sulfonated carbonaceous solid acid. Fuel Process Technol. 2018; 169: 244-247.

Shuai L, Pan X. Hydrolysis of cellulose by cellulasemimetic solid catalyst. Energy Environ Sci. 2012; 5: 6889-6894.

Takagaki A, Nishimura M, Nishimura S, Ebitani K. Hydrolysis of Sugars Using Magnetic Silica Nanoparticles with Sulfonic Acid Groups. Chem Lett. 2011; 40: 1195-1197.

Wang T, Gallo JMR, Shanks BH, Dumesic JA. Production of 5-Hydroxymethylfurfural from Glucose Using a Combination of Lewis and Brønsted Acid Catalysts in Water in a Biphasic Reactor with an Alkylphenol Solvent. Catalysis. 2012a; 2: 930934.

Wang T, Gallo JMR, Shanks BH, Dumesic JA. Production of 5-Hydroxymethylfurfural from Glucose Using a Combination of Lewis and Brønsted Acid Catalysts in Water in a Biphasic Reactor with an Alkylphenol Solvent. ACS Catal Lett. 2012b; 2012: 930-934.

Ya'aini N, Amin NAS, Asmadi M. Optimization of levulinic acid from lignocellulosic biomass using a new hybrid catalyst. Bioresour Technol. 2012; 116: $58-65$.

Yan L, Liu N, Wang Y, Machida H, Qi X. Production of 5-hydroxymethylfurfural from corn 
stalk catalyzed by corn stalk-derived carbonaceous solid acid catalyst. Bioresour Technol. 2014; 173: 462-466.

Yang F. Fu J, Mo J, Lu X. Synergy of Lewis and Brønsted acids on catalytic hydrothermal decomposition of hexose to levulinic acid. Energy and Fuels. 2013; 27: 6973-6978.

Yang G, Pidko EA, Hensen EJM. Mechanism of Bronsted acid-catalyzed conversion of carbohydrates. J Catal. 2012; 295: 122-132.

Yu IKM, Tsang DCW. Conversion of biomass to hydroxymethylfurfural: A review of catalytic systems and underlying mechanisms. Bioresour Technol. 2017; 238: 716-732.

Yu IKM, Tsang DCW, Yip ACK, Chen SS, Wang L. Catalytic Valorization of Starch-Rich Food Waste into Hydroxymethylfurfural ( HMF ): Controlling Relative Kinetics for High Productivity. Bioresour Technol. 2017; 237: 222-230.

Zhang L, Xi G, Zhang J, Yu H, Wang X. Efficient catalytic system for the direct transformation of lignocellulosic biomass to furfural and 5-hydroxymethylfurfural. Bioresour Technol. 2017; 224: 656-661.

Zhang X, Hewetson BB, Mosier NS. Kinetics of maleic acid and aluminum chloride catalyzed dehydration and degradation of glucose. Energy and Fuels. 2015; 29: 2387-2393.

Zhang Z, Zhao ZK. Microwave-assisted conversion of lignocellulosic biomass into furans in ionic liquid. Bioresour Technol. 2010; 101: 1111-1114.

Zhou C, Zhao J, Elgasim A, Yagoub A, Ma H. Conversion of glucose into 5-hydroxymethylfurfural in different solvents and catalysts : Reaction kinetics and mechanism. Egypt J Pet. 2018; 26: 477-487.

Zhou P, Zhang Z. One-pot catalytic conversion of carbohydrates into furfural and 5-hydroxymethylfurfural. Catal Sci Technol. 2016; 6: 3694-3712. 